\title{
nature
}

\section{Waking up to the importance of sleep}

\section{A growing chasm separates the growing scientific understanding of sleep, and the widespread public assumption that it just doesn't matter.}

s a full night's sleep an essential ingredient for a healthy mind and body, or just a luxury for the lazy? Despite extensive evidence for the former, the tendency of society (including hypercompetitive heads of laboratories) to applaud people who daim to be forever on the go leaves many assuming the latter. The notion that successful people can get by with just a few hours of sleep a night reinforces a common perception that sleep is a waste of time.

This misperception carries serious ramifications. The tendency to sleep less - perhaps $20 \%$ less in industrialized countries than a century ago - has serious consequences for public safety. In a poll funded by the US National Science Foundation (NSF), more than one-third of American drivers admit to having nodded off behind the wheel. Public disasters such as the 1989 Exxon Valdez oil-tanker accident have been attributable, in large part, to sleep deprivation. Furthermore, a mounting body of evidence links a lack of sleep to mood swings, depression, anxiety and other mental illness.

The medical profession has been slow to acknowledge all this. According to the same NSF poll (www.sleepfoundation.org), 75\% of patients report sleep problems, but less than one-third say their doctor has asked them about it. And trainee physicians seem to be trained to wear their own sleep deprivation as a badge of honour, rather than what it is - a threat to health, safety and professionalism.

A Nature Insight on sleep in this issue (see page 1253) sheds some fascinating light on sleep research. It explores questions ranging from what we might learn about the function of sleep by studying the variation in sleep patterns between different mammals, to whether sleep is essential for some forms of memory consolidation.

Sleep is much more than an absence of activity in the body and brain. The brain is highly active during sleep, especially during REM sleep, which is characterized by rapid eye movements and vivid dreaming. Sleep is also far from the single phenomenon it is sometimes assumed to be: the brain activities behind its different stages can be as distinct from each other as they are from wakefulness.

Although answers to some of the most basic questions in sleep research - such as why we sleep at all - remain elusive, recent developments do provide knowledge that is directly relevant to public health and safety. Despite the common perception that falling asleep is a gradual process, for example, the transition from being awake to being asleep can be extremely rapid.

On page 1257 of this issue, Harvard neuroscientist Clifford Saper and his colleagues describe how a 'flip-flop' switch in the part of the brain known as the hypothalamus brings about discrete transitions between waking and sleeping. They show how damage to this switching mechanism can lead to instabilities in both sleeping and waking states, as seen in narcolepsy, a debilitating neurological disease. The very concept of a switch that seems optimized to flip rapidly between being asleep and awake, without an intermediate state, should give pause to anyone tempted to drive or operate machinery when feeling drowsy.

Researchers should, however, be cautious about overplaying data that link sleep with illness. Both heart disease and obesity, for example, have been linked

"Neuroscience research has a role not just in building our understanding of sleep, but also in helping to convince the public to take it seriously."

to sleep problems in some studies. But despite clear signs of a correlation, evidence of a causal link remains inconclusive.

It would be naive to think that simply laying out the scientific facts will change popular perceptions about sleep and behaviour. Data proving the link between smoking and lung cancer, for example, were available long before behaviour changed on a significant scale. Even with the assistance of extensive public information campaigns, the message took a long time to sink in.

Nonetheless, basic neuroscience research has a role not just in building our understanding of sleep, but also in helping to convince the public to take it seriously. Public communication of important findings should be helped by the fact that so many people find the topic fascinating. Basic researchers, clinicians and educators can take advantage of this interest to make the case for changes in behaviour - while ensuring that they, too, get a good night's sleep.

\section{Is the city safe?}

\section{The Environmental Protection Agency is ducking a frank assessment of New Orleans after Katrina.}

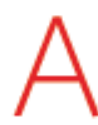
fter the terrorist attacks of 11 September 2001, the US Environmental Protection Agency (EPA) took some flak for declaring, perhaps prematurely, that the air was safe in the vicinity of the World Trade Center in New York.

Now the agency, which is charged with protecting public health and the environment, is abdicating its responsibility to issue clear public guidance on possible health hazards in New Orleans, flooded last month by Hurricane Katrina. It is saying nothing on the advisability of returning to the ruined city, arguing instead that its job is just to run tests and pass on data to local officials, who will make of them what they will.

For what was once the world's foremost environmental agency, this simply isn't good enough. The EPA's own scientific advisory board, as well as the usual welter of environmental groups, are rightly calling on the agency to do its job properly, and give the American people more solid information about the environmental 
risks posed by episodes such as the flooding after Hurricane Katrina (see page 1216).

Members of the science advisory board are unhappy with the tests that were carried out in the first days, when the city was still under water. Tests were done for many regulated chemicals, but those for more obvious threats, such as disease-causing microbes, were not. According to Granger Morgan, a technology policy expert at Carnegie Mellon University in Pittsburgh and chairman of the EPA science advisory board, the agency needs to prepare better plans for specific emergency situations, so that it can respond appropriately.

Most of the data currently being collected by the agency on the ground in New Orleans pertain only to short-term risks. Levels of metals or pesticides in the sediment left behind as the floodwater receded are being compared with exposures that are safe for a few days, or even less. People who want to find out whether the levels of contaminants near their homes are dangerous in the longer term will have to do their own research.

The agency can hardly be accused of sitting around twiddling its thumbs in New Orleans. It has more than 1,000 employees working in the ravaged track of the storm, and is doing its best to advise members of public about how best to protect themselves from contaminants. Hundreds of measurements have been carefully posted on its website (www.epa.gov/katrina). All of this has been done within the agency's existing and rather overstretched budget.

People are moving back into New Orleans now, pushing their way into mud-caked buildings, sleeping in rotting, oily houses, and scrubbing mould off the walls without wearing protection - or, in at least one case, with respirators gamely strapped on upside-down.

Naturally, the political pressure to repopulate the area is intense. There is nothing to suggest that the city should be declared uninhabitable. But the public deserves much more than statements such as one issued on 17 September, to the effect that neither the EPA nor the Centers for Disease Control and Prevention in Atlanta, Georgia, will come forward to offer any guid-
"EPA needs to be prepared to assert its opinion and judgment on matters that impact human health and the environment, regardless of who else is involved." ance on the reinhabitation of New Orleans.

As the EPA's own inspector-general declared in 2003: "EPA needs to be prepared to assert its opinion and judgment on matters that impact human health and the environment, regardless of who else is involved or may share responsibility. Ultimately, the public, Congress, and others expect EPA to monitor and resolve environmental issues." In the wake of Katrina, the need for the agency to fulfil that role is clearer than ever.

\section{Free tips}

\section{The National Academies offers guidance to keep the United States internationally competitive.}

W orthy reports are as frequently encountered in Washington DC as grand monuments - and are just as likely to be ignored by the locals. But lawmakers will fail their constituents if they manage to ignore the latest study on competitiveness by the National Academies.

The report, Rising Above the Gathering Storm, addresses resurgent fears that the United States' longstanding global leadership in research and development is on the wane. Written by a panel chaired by Norman Augustine, former chief executive of technology corporation Lockheed Martin, it offers several concrete recommendations designed to keep that leadership intact. Whether the US government pays any attention or not, its competitors will find the panel's findings well worth a look.

Whereas previous studies of this kind have focused primarily on research funding, this one concentrates much of its attention on improving the nation's scientific literacy. It calls for the annual recruitment of some 10,000 science and maths teachers, proposing that science undergraduates be lured into the classroom with generous scholarships, with the lofty goal of improving science education at school for some 10 million people.

This proposal may appear to some US politicians to be central planning run amok - and it doesn't really address the low pay and social standing of teachers in the United States. But it does have potential and precedent: an existing programme called Teach for America has succeeded in recruiting thousands of young college graduates to teach in the nation's most troubled neighbourhoods.

Other recommendations of note include a call for the creation of a new energy-research agency that would conduct low-cost, highrisk, high-reward research projects. This would be modelled on the Defense Advanced Research Projects Agency (DARPA), which has been highly successful in backing exciting, basic research that may spawn useful technology. Another new entity would be set up expressly to arrange for the construction of scientific facilities.

The academy panel also proposes radical changes in the treatment of young scientists in general, and foreign ones in particular. It suggests a new category of generous grants that would allow young researchers early in their career to firmly establish their own lines of enquiry. Furthermore, it calls for changes in US immigration policy that would make it easier for foreign students and scientists to stay in the country to continue their careers. Both these suggestions will require serious political commitment to implement - but they would
"Some of these suggestions will require serious political commitment to implement - but they would go a long way towards fostering fresh scientific talent." go a long way towards fostering fresh scientific talent.

Senators Lamar Alexander (Republican, Tennessee) and Jeff Bingaman (Democrat, New Mexico), who commissioned the study, must now try to drum up support on Capitol Hill for the implementation of its recommendations. They face an uphill battle, given the size of the US budget deficit and inevitable political resistance to such concepts as further federal involvement in school education. The United States' competitors, in Europe and the Far East, also need to consider such measures, and might actually find some of them easier to implement. 